\title{
Paraparesis Following Spinal Cord Stimulator Trial, Implantation and Revision
}

\section{TO THE EDITOR}

Smith et al are to be congratulated for presenting a series of 4 difficult cases that demonstrate the risk of paraparesis as a postoperative complication of spinal cord stimulator trial, placement or revision (1). Although the most common complications from these procedures involve equipment failure without neurologic injury, these cases underscore the importance of weighing all postoperative risks.

In 20 years of practice as a neurosurgeon, we have seen only one case of paraparesis linked to spinal cord stimulator implantation. That patient presented to a local hospital with a delayed epidural abscess from a stimulator implanted years before by another provider. She had urinary retention, 2/5 movement in one toe, and complete midthoracic block on computer tomography (CT) myelogram. Under our care, she underwent thoracic laminectomy resulting in a positive, uneventful outcome.

Smith et al also describe the appropriate workup and treatment in spinal cord stimulator trial, placement or revision. Regarding Case 4, they report that, after the spinal cord stimulator was removed, computer tomography (CT) scan of the thoracic spine showed multilevel, partially calcified disc herniations at T6-T7, T7-T8, and T8-T9 (Fig. 4). We reviewed Fig. 4, labeled T2-weighted MRI, and we concur with the authors that this image shows herniations at T6-T7, T7T8, and T8-T9. However, our review of the image also suggests a disc protrusion and rupture at T4-T5, which would raise the possibility that the patient may have had preexisting thoracic disc ruptures. For that reason, we wonder whether any preoperative thoracic MRI or preoperative thoracic CT scans were performed. If preoperative studies were not available, Fig. 4 may demonstrate the value of preoperative, baseline imaging.

Furthermore, we believe this series of case studies also underscores the need for MRI-compatible electrodes and generators. Without MRI compatibility, post-implantation treatment options are limited to myelogram, CT scan, or postmyelo CT.

John W. Gilbert, MD, Medical Director

Greg R. Wheeler, MD

Gregory E. Mick, DO

Stephanie L. Herder, MD

Gay B. Richardson, MD

Spine and Brain Neurosurgical Center

PO Box 22430

Lexington, $\mathrm{KY}$

E-mail: correspondence@sbncmd.com

\section{Reference}

1. Smith CC, Lin JL, Shokat M, Dosanjh SS, Casthely D. A report of paraparesis following spinal cord stimulator trial, implantation and revision. Pain Physician 2010; 13:357-363. 